\title{
Rare case report of mermaid baby: sirenomelia
}

\section{Pinki Mazumdar*, Pranoy Nath}

Department of Obstetrics and Gynecology, Silchar Medical College, Assam, India

Received: 23 February 2021

Accepted: 01 April 2021

\section{*Correspondence:}

Dr. Pinki Mazumdar,

E-mail: pin.mazumder4@gmail.com

Copyright: () the author(s), publisher and licensee Medip Academy. This is an open-access article distributed under the terms of the Creative Commons Attribution Non-Commercial License, which permits unrestricted non-commercial use, distribution, and reproduction in any medium, provided the original work is properly cited.

\begin{abstract}
Sirenomelia or mermaid baby is a rare and fatal congenital anomaly. It is characterized by varying degrees of fusion of lower limbs, thoracolumbar spinal anomalies, sacrococcygeal agenesis, genitourinary malformations, lower gastrointestinal tracts anomalies (e.g. renal agenesis, absent bladder, anorectal atresia) and absent internal genitalia. Most of the cases are associated with Potter's facies and pulmonary hypoplasia. The incidence of the disease was 0.8 1 case/1,00,000 births and male to female ratio being 3:1. We reported a case of 19 years old primi at 35 weeks 3 days of gestation with history of tobacco intake during pregnancy who delivered a $1.24 \mathrm{~kg}$ baby with single fused lower limbs with a rudimentary tail and multiple congenital anomalies .There was also evidence of Potter's facies .The baby died within 20 mins after birth. Sirenomelia is a rare but lethal congenital anomaly. Prevention is possible and when diagnosed antenatally, termination should be offered.
\end{abstract}

Keywords: Fusion of lower limbs, Sirenomelia, Mermaid baby, Potter's facies

\section{INTRODUCTION}

Mermaid syndrome or sirenomelia is a rare congenital anomaly which is characterized by varying degrees of fusion of lower limbs, thoracolumbar spinal anomalies, sacrococcygeal agenesis, genitourinary malformations and lower gastrointestinal tract anomalies (e.g. renal agenesis, absent bladder, anorectal atresia) and absent internal genitalia. ${ }^{1}$ It was first described in 1542 by Rocheus and 1553 by Palfyn and this syndrome called after the mythical Greek sirens. ${ }^{2}$

The disorder most commonly known as the mermaid syndrome since the fusion of both lower limbs gives a appearance of mermaid but it has equally been referred as symmelia, sympodia, monopodia and sympus. It is described as the most severe form of caudal regression syndrome. Mermaid syndrome is a fatal congenital disorder because of underlying visceral anomalies but there are number of surviving cases reported after reconstructive surgery.

The incidence of this rare congenital anomaly is 0.8 $1 / 1,00,000$ births, the male and female ratio being 3:13. The incidence in monozygotic twins were reported 150200 times. Sirenomelia syndrome is more likely to be seen in diabetic mother, about $15 \%$ of mothers had gestational diabetes mellitus during pregnancy. ${ }^{4}$

Mermaid baby syndrome has a strong association with maternal diabetes mellitus with 1:200-250 relative risk and $22 \%$ of mermaid baby will have diabetic mother. ${ }^{5}$

Though this is a rare congenital malformation of uncertain etiology but some etiological factors are considered a cause for sirenomelia like intake of haloperidol and tobacco antenatally. Cadmium, lead, vitamin A are other proposed teratogens. Nutritional 
deficiency has also been proposed as a possible etiological factor.

We report a case of sirenomelia with no history of maternal drug abuse or maternal diabetes from Assam $(\mathrm{SMCH})$ and the associated findings.

\section{CASE REPORT}

A 19 years old primi at 35 weeks 3 days of gestational age was admitted in labour room in first stage of labor with decreased fetal movement with mild anaemia $(\mathrm{Hb}-$ $9.4 \mathrm{gm} \%$ ). Patient was from low socioeconomic background from rural area with history of one antenatal checkup and no investigations except $\mathrm{Hb}$ report. USG done after admission which shows 32 weeks of gestation with oligohydramnios, $1.6 \mathrm{~kg}$ baby weight with cephalic presentation with fundobody anterior placenta. No comment was made on the presence or absence of malformations. Patient was from a rural area of Assam, where betal nut and tobacco is commonly used. There was history of tobacco intake before and during the pregnancy. Her pregnancy was otherwise uneventful and there was no history of diabetes, hypertension, thyroid disorder or fever in first trimester. Her husband was 24 years old and there was no history of genetic and congenital anomaly in the family. This pregnancy resulted from a non consanguinous marriage. During admission patient is hemodynamically stable and afebrile but fetal heart sound could not be localised. Patient was managed conservatively and prophylactic antibiotic was given and all necessary investigations sent. Dexamethasone was given and after 22 hours patient was complaining of labor pain and on per vaginal examination revealed a fully dilated cervix with cephalic presentation at station 0 .

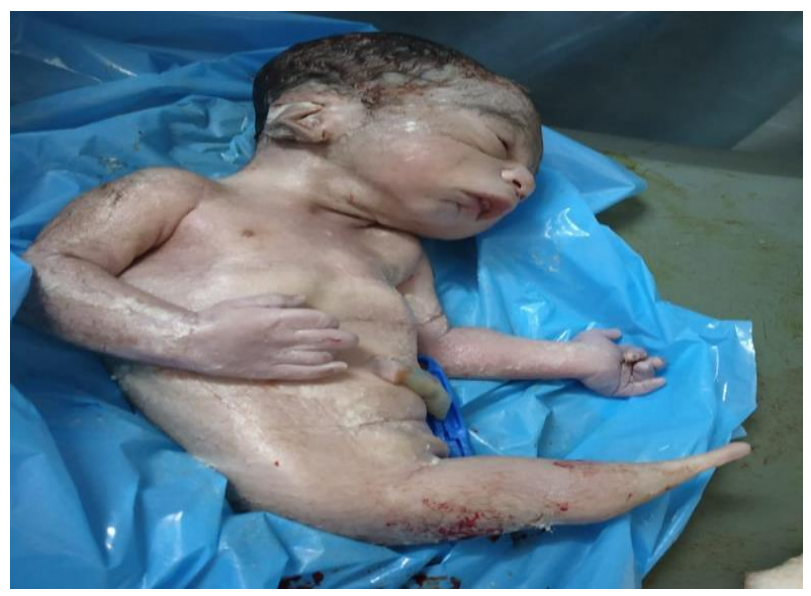

Figure 1: Complete picture of mermaid baby.

She delivered a $1.24 \mathrm{~kg}$ baby with single fused lower limbs with a rudimentary tail and multiple congenital anomalies as shown in Figure 1. There was very less amount of amniotic fluid drained at the time of delivery. The APGAR score was 3 at 1 and 5 minutes. Baby did not cry after birth and resuscitation done by a pediatrician.

On physical examination, the infant showed fused lower limbs with a rudimentary tail. Infant showed narrow chest indicating lung hypoplasia. Infant had ambiguous genitalia, there was no anal opening. There was also evidence of Potter's facies (prominent epicanthal folds, downward flat nose, receding chin, low set soft dysplastic ears and small slit like mouth) (Figure 2).

The baby died within 20 mins after birth and parents declined a postmortem examination. Intrapartum and postpartum period was uneventful for the patient. Patient had normal blood sugar level in postpartum period.

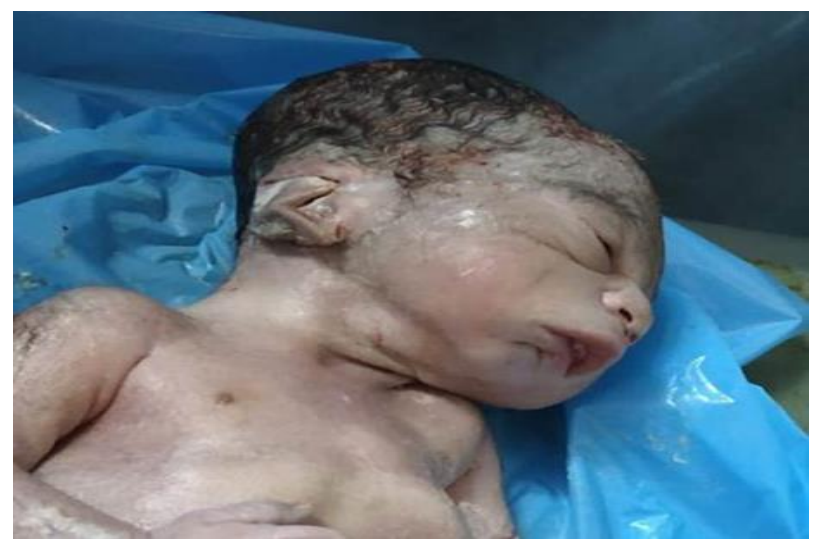

Figure 2: Potter's facies showing prominent epicanthal folds, downward flat nose, receding chin, low soft dysplastic ears and small slit like mouth.

\section{DISCUSSION}

Sirenomelia is a rare but lethal congenital anomaly. Till now approximately 300 cases of sirenomelia are reported worldwide and 14 cases reported from India. Sirenomelia is a fatal congenital anomaly because of multi organ dysfunction along with fused lower limbs still 9 mermaid syndrome cases have been reported who survived after reconstructive surgery. ${ }^{6}$ After delivery most of the cases diagnosed as sirenomelia but it can be diagnosed by using high resolution or color Doppler sonography as early as 13 weeks of pregnancy. ${ }^{7}$ In most of the cases ultrasonography shows oligohydramnios.

Sirenomelia is characterized by partial or complete fusion of lower limbs and associated with other anomalies including bilateral renal agenesis or dysgenesis, complete or partial agenesis of genitourinary system, imperforate anus, absence or ambiguous external genitalia, lung hypoplasia, single umbilical artery, vertebral and cardiac anomalies and presence of aberrant vasculature.

The 3 different degrees of lower extremities fusion are (a) symelia apus: in this condition no feet are present and the limbs are completely fused in to a single limb, one femur and one tibia are present in such cases. Our case fits into 
this category, (b) symelia unipus: one foot is present with 2 femurs, 2 tibia and 2 fibulae, (c) symelia dipus: in this case two feet are present giving appearance of fins and fusion of the limbs extends up to ankles.

The molecular defect which resulting in mermaid baby syndrome remains unclear. Two hypothesis are proposed for this condition. They are vascular steal hypothesis, defective blastogenesis hypothesis.

According to vascular steal hypothesis fusion of lower limbs in sirenomelia occurs due to deficient blood supply and nutrient supply to the caudal mesoderm, which leads to agenesis of midline structures and subsequent varying degrees fusion of both lower limbs. ${ }^{8}$

The embryological and pathological causes of this condition occur before the 4th week and affect the structures which derived from the caudal mesodermal axis of the embryo. ${ }^{9}$

Teratogenic event that occurs during the gastrulation stage results in the primary defect in the development of caudal mesoderm. This is explained as per defective blastogenesis hypothesis. Some environmental factors are proposed for this condition are maternal diabetes ,tobacco use, retinoic acid and heavy metal exposure.

In our case, there was history of tobacco use before or during pregnancy but no history of teratogenic drugs or radiation exposure during pregnancy. Maternal blood glucose level was normal.

Potter's facies usually found in sirenomeliac infants which includes prominent epicanthal fold, hypertelorism, flat nose, low set ears, receding chin. In our case, features of Potter's facies were present.

\section{Stocker and Heifetz classification}

This classification based on presence or absence of bones in the lower limbs. ${ }^{10}$ Type I: femur and tibia bones are formed, type II: single fibula bone, type III: fibula bone absent, type IV: partially fused femurs, fused fibulae, type V: two femurs partially fused, type VI: single femur and single tibia, type VII: only femur present, there is no tibia.

\section{CONCLUSION}

Sirenomelia is a rare but lethal congenital anomaly but a peculiar syndrome. Controversies are still persisting on its etiopathogenesis. However, prevention is possible and when diagnosed antenatally, termination should be offered. Prevention from exposure to teratogenic drugs should be maintained and optimum blood glucose level should be maintained in preconceptional period and in first trimester. Every patient should be counselled for regular antenatal checkup. Because this malformation is incompatible with life, an early scan between 11-13 weeks is recommended to diagnose the anomaly so that termination of pregnancy can be planned at the earliest.

Funding: No funding sources

Conflict of interest: None declared

Ethical approval: Not required

\section{REFERENCES}

1. Valenzano M, Paoletti R, Rossi A, Farinini D, Garlaschi G, Fulcheri E. Sirenomelia Pathological features, antenatal ultrasonographic clues and a review of current embryogenic theories. Hum Reprod Update. 1999;5(1):82-6.

2. Keirsblick JV, Cannil M, Robrechts C, Ravel TD, Dymarkowski S, Bosch TVD, et al. First trimester diagnosis of sirenomelia. Prenat Diagn. 2006;26(8):684-8.

3. Reddy KR, Srinivas S, Kumar S, Reddy S, Prasad H, Irfan GM. Sirenomelia a rare presentation. J Neonat Surg. 2012;1(1):7.

4. Sikandar R. Munim S. Sirenomelia, the mermaid syndrome: case report and a brief review of literature. J Pak Med Assoc. 2009:59(10):721-3.

5. Aslan H, Yanik H, Celikaslan N, Yildirim G, Ceylan Y. Prenatal diagnosis of caudal regression syndrome: a case report. BMC Preg Childbirth. 2001;1(8):8.

6. Romano S , Esposito V ,Fonda C ,Russo A, Grassi R. Beyond the myth: the mermaid syndrome from homeus to Anderson a tribute to Hans Christian Anderson's bicentennial of birth. Eur J Radiol. 2006;58(2):252-9.

7. Vijayraghavan SB, Amudha AP. High resolution sonographic diagnosis of sirenomelia. J Ultrasound Med. 2006;25(4):555-7.

8. Sadler TW, Rasmussen SA. Examining evidence for vascular pathogenesis of selected birth defects. Am J Med Genet A. 2010;152A(10):2426-36

9. Taghvi MM, Jafari N, Shariati M, Morteza ZF. Sirenomelia (mermaid syndrome): An infant from parents who used a special form of snuff. Pak J Biol Sci. 2009;12(9):722-5.

10. Stocker JT, Heifitz SA. Sirenomelia: a morphological study of 33 cases and review of the literature. Perspect Pediatr Pathol. 1987;10:7-50.

Cite this article as: Mazumdar P, Nath P. Rare case report of mermaid baby: sirenomelia. Int J Reprod Contracept Obstet Gynecol 2021;10:2088-90. 